\title{
A New Magnetless Flux-Reversal HTS Machine for Direct-Drive Application
}

\author{
Christopher H. T. Lee, K. T. Chau, Fellow, IEEE, Chunhua Liu, Senior Member, IEEE, \\ T. W. Ching, Senior Member, IEEE, and Mu Chen
}

\begin{abstract}
The concepts of axial-flux (AF) structure and the high-temperature superconductor (HTS) excitation are newly applied into the flux-reversal (FR) machine in this paper. With such application, a new magnetless AF-FRHTS machine is formed. The proposed machine inherently provides a bipolar flux-linkage to enhance the performance, so that its torque density can be comparable to the permanent-magnet (PM) counterparts. In addition, the proposed machine makes an improvement on the torque density and the flux-regulating capability for the wide-speed range operation through the external HTS excitation. Based upon all these characteristics, the AF-FRHTS machine becomes more favorable for hybrid electric vehicle (HEV) applications. To be specific, the proposed machine is designed and evaluated based on the standards suggested for typical passenger HEVs. The corresponding performances of the AF-FRHTS machine are analyzed by using the 3D finite element method (3D-FEM).
\end{abstract}

Index Terms-Magnetless, flux-reversal, axial-flux, directdrive, hybrid electric vehicle.

\section{INTRODUCTION}

$\mathrm{W}$ ITH an emphasis on sustainable development in recent years, researchers are paying more attention to energy efficiency and environmental impact in the development of the electric machines (EVs) [1]. Generally speaking, the electric machines are expected to provide high efficiency, high power density, high controllability, wide-speed range, and maintenance-free operation [2]. The flux-reversal permanentmagnet (FRPM) machines, which can achieve all these goals and are particularly favorable for direct-drive applications, have long been actively developing [3,4]. Similar to other bipolar flux-linkage machines, the FRPM machine can also offer larger power density, as compared with the conventional unipolar flux-linkage machines [5]. However, the limited and fluctuating supply of the PM materials leads to the surged material cost [6]. The advancement of magnetless machines has attracted more attention as a result [7]. The magnetless machines enjoy the absolute merit of cost-effectiveness, yet

Automatically generated dates of receipt and acceptance will be placed here; authors do not produce these dates. This work was supported by the Hong Kong Research Grants Council, Hong Kong Special Administrative Region, China (Project No. 17200614).

C. H. T. Lee, K. T. Chau, C. Liu and M. Chen are with the Department of Electrical and Electronic Engineering, The University of Hong Kong, Pokfulam, Hong Kong (email: ktchau@eee.hku.hk).

T. W. Ching is with the Department of Electromechanical Engineering, The University of Macau, Macau. suffer from a relatively lower torque density when compared with the PM machines.

The axial-flux (AF) machine can definitely expand the torque density, by utilizing the radial length as an active part for torque production, as compared with its radial-flux (RF) counterparts $[8,9]$. Even though the torque improvement of the high-temperature superconductor (HTS) application has been confirmed [10], the implementation between the AF structure and HTS-field has never been addressed.

This paper aims to newly incorporate the HTS winding into the AF machine, so as to produce the new AF-FRHTS machine intentionally for the in-wheel direct-drive application. The design criteria and operating principle of the proposed magnetless machine will be discussed later in this paper. The performance of the proposed machine will be analyzed by using the 3D finite element methods (3D-FEM), and then quantitatively compared with the typical passenger hybrid electric vehicle (HEV) standards.

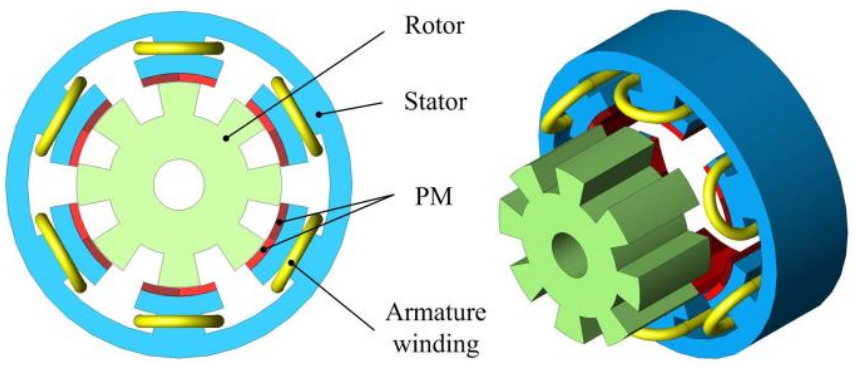

(a)
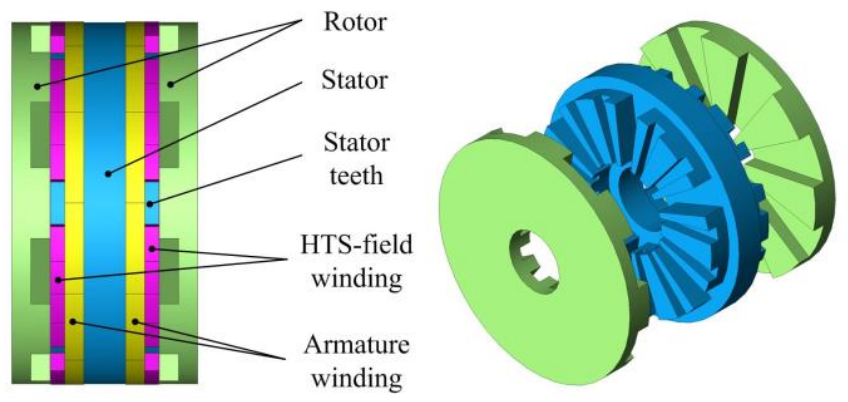

(b)

Fig. 1. The flux-reversal (FR) machines: (a) Conventional RF-FRPM. (b) Proposed AF-FRHTS.

\section{Proposed Machine Structure}

The topologies of the conventional RF-FRPM machine [3, 4] and the proposed magnetless 6/8-pole AF-FRHTS machine are shown in Fig. 1(a) and Fig. 1(b), respectively. The threephase AF-FRHTS machine adopts the sandwiched-stator sided-rotors topology. By designing with the suitable 
dimensions, the rotors of the proposed machine can be mounted to the tires directly, hence fulfilling the in-wheel motor drive applications intuitively [9]. The proposed machine adopts one of the most common wheel sizes, ie: 195/65 R15, denoting the axial length and the rim diameter are $195 \mathrm{~mm}$ and 15 inch (or $381 \mathrm{~mm}$ ), respectively. By considering the typical requirements of a passenger $\mathrm{HEV}$, the targeted machine specifications are listed in Table I [9].

Because the AF-FRHTS machine is extended from the conventional RF-FRPM machine, its design equations such as the pole arrangement $[3,4]$ can be derived from the traditional RF-FRPM machine. Hence, the pole arrangements for proposed AF-FRHTS machine are given by

$$
\left\{\begin{array}{l}
N_{s}=2 m k \\
N_{r}=N_{s}+2 k
\end{array}\right.
$$

where $N_{s}$ is the number of stator poles, $N_{r}$ the rotor poles, $m$ the armature phases and $k$ is any integer. By selecting $m=3$, and $k=1$, this ends up with $N_{s}=6, N_{r}=8$ and comes up with the proposed structure of the proposed machine.

The profound FRPM machine has the conventional structure with multi-pole PMs of alternating polarities allocated on each of the corresponding stator pole. The PM flux-linkages reverse the signs in accordance to its rotor positions [3, 4]. The typical flux pattern of the conventional RF-FRPM machine is shown in Fig. 2. By adopting the suitable HTS winding arrangements, the proposed machine can also achieve the same flux-linkage patterns as the FRPM machine. To be specific, the HTS windings are allocated on the stator slot in a way to provide the alternating polarities, hence mimicking the PM pole-pair arrangement of the FRPM machine. For the proposed AFFRHTS machine, when its rotors rotate from position 1 to 2, as shown in Fig. 3, its HTS flux-linkages reverse its directions, similar to the FRPM machine. Therefore, the proposed machine can provide the bipolar flux-linkages, same as the FRPM machine does. With the bipolar flux-linkage characteristic, the AF-FRHTS machine can result in better power and torque densities than the unipolar flux-linkage counterparts do [5].

TABLE I. TARGET MOTOR SPECIFICATIONS FOR NORMAL HEV APPLICATIONS [9]

\begin{tabular}{ll}
\hline \hline Item & Value \\
\hline Peak DC voltage & $360 \mathrm{~V}$ \\
Rated power & $3.1 \mathrm{~kW}$ \\
Rated torque & $100 \mathrm{Nm}$ \\
Constant-torque operation & $0-300 \mathrm{rpm}$ \\
Constant-power operation & $300-900 \mathrm{rpm}$ \\
Peak power & $140 \%$ for $60 \mathrm{~s}$ \\
Wheel & $195 / 65 \mathrm{R} 15$ \\
\hline \hline
\end{tabular}

\section{OPERATING PRINCIPLE}

The proposed AF-FRHTS machine arranges the HTSwinding with the concentrated winding arrangement on its sandwiched-stator teeth, resulting as the HTS flux-linkages flow along the two sided-rotors with the identical paths as shown in Fig. 3. Because the two independent machine segments are designed as the same structure, it is believed that both of them can offer the same results without distortion to each other. To simplify the operation complexity, the two sided-rotors are purposely operated with the single set of three-phase armature winding.

Upon the HTS-field excitations, the proposed machine can be operated with the brushless DC (BLDC) operation [10]. At the time when the flux-linkage is going upwards, no matter in the positive or negative ranges, a positive rectangular current $I_{\text {rect }}$ is applied to result in a positive torque. On the other hand, when a negative rectangular current $-I_{\text {rect }}$ is applied and the flux-linkage is going downwards, the torque produced is still positive. The theoretical operating waveforms are shown in Fig. 4 and the operating equations are given by

$$
\begin{cases}I_{\text {armature }}=I_{\text {rect }} & \theta_{1}<\theta<\theta_{2} \\ I_{\text {armature }}=0 & 0 \leq \theta \leq \theta_{1}, \theta_{2} \leq \theta \leq \theta_{3}, \theta_{4} \leq \theta \leq 2 \pi \\ I_{\text {armature }}=-I_{\text {rect }} & \theta_{3}<\theta<\theta_{4}\end{cases}
$$

With the BLDC operation, all the torque-producing zones can be utilized and the torque ripple is suppressed. Each of the armature phases perform $120^{\circ}$ conduction where $\theta_{2}-\theta_{1}=\theta_{4}$ $-\theta_{3}=120^{\circ}$ and the developed torque is governed as

$T_{A F-F R H T S}=\frac{1}{2 \pi} \int_{0}^{2 \pi}\left(I_{\text {rect }} \frac{d \psi_{A F-F R H T S}}{d \theta}+\frac{1}{2} I_{\text {rect }}^{2} \frac{d L_{A F-F R H T S}}{d \theta}\right) d \theta$

where $\Psi_{A F-F R H T S}$ and $L_{A F-F R H T S}$ are the HTS flux-linkages and the armature self-inductance, respectively. As given in equation (3), the produced torque of the proposed machine is comprised of two torque components, namely the HTS-field torque and the reluctance torque components. The developed torque is majorly contributed by HTS-field torque component, while the reluctance torque component is the pulsating part regarding the averaged zero value [10].

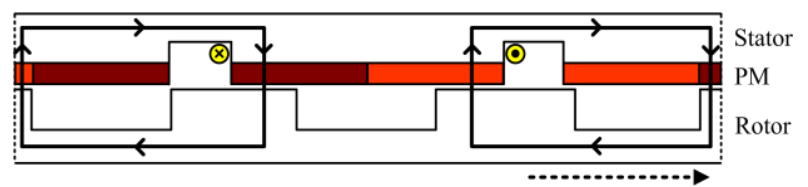

Fig. 2. Flux patterns of the conventional RF-FRPM.
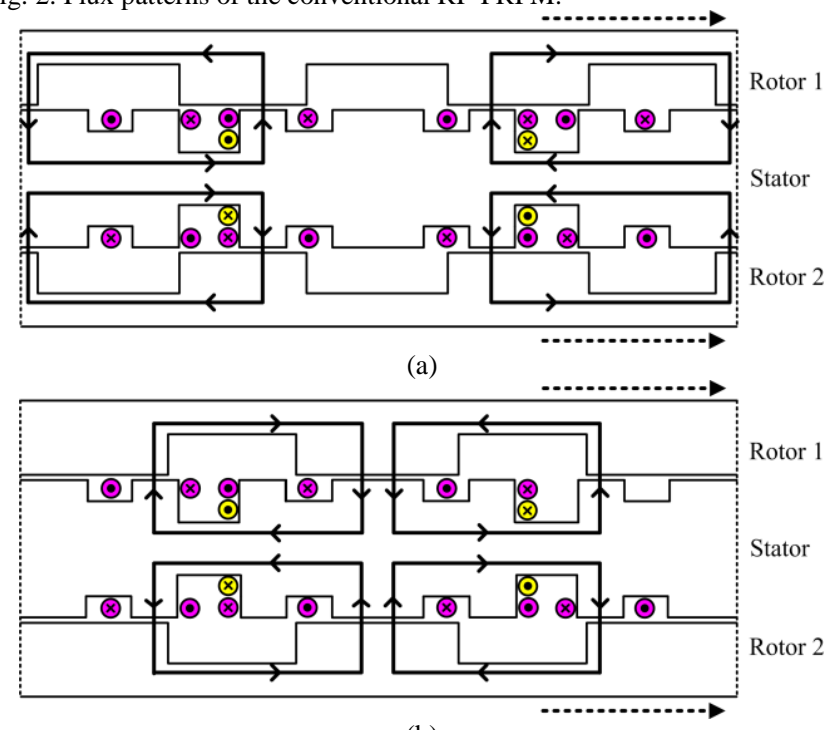

(b)

Fig. 3. Flux patterns of AF-FRHTS: (a) Position 1. (b) Position 2. 


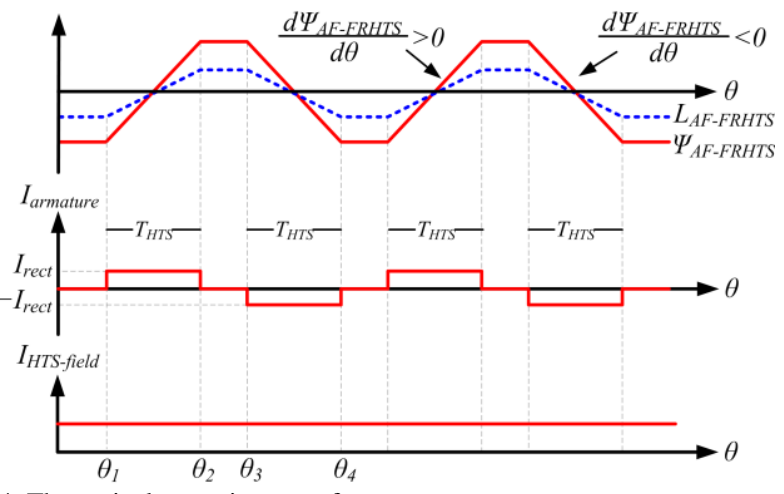

Fig. 4. Theoretical operating waveforms.

\begin{tabular}{ll}
\multicolumn{2}{c}{ TABLE II. MACHINE KEY DATA } \\
\hline \hline Item & AF-FRHTS \\
\hline Radial outside diameter & $381.0 \mathrm{~mm}$ \\
Radial inside diameter & $100.0 \mathrm{~mm}$ \\
Airgap lengths & $0.5 \mathrm{~mm}$ \\
Axial stack length & $195.0 \mathrm{~mm}$ \\
Rotor pole number & 8 \\
Stator pole number & 6 \\
No. of phases & 3 \\
Slot-fill factor & $60 \%$ \\
No. of armature turns & 120 \\
Rotor and stator material & Steel sheet: 50JN700 \\
Armature winding material & Copper \\
HTS-field material & BSCCO-2223 \\
\hline \hline
\end{tabular}

\section{Performance ANAlysis}

The major design data of the proposed machine is listed in Table II. The machine performances of the proposed machine can be simulated by using the 3D-FEM, and then quantitatively compared. The 3D-FEM is accomplished by employing the JMAG-Designer as the magnetic solver, while each simulation process takes more than 10 hours to finish, with an aid of a high-performance PC. The no-load magnetic flux distributions of the AF-FRHTS are shown in Fig. 5. The results agree well with the theoretical expectations as suggested in Fig. 3, hence confirming the flux-linkages to obtain the expected patterns.

First of all, the flux-linkages of AF-FRHTS are shown in Fig. 6. It can be shown that the flux-linkages of both armature windings are identical. Both of them are well balanced among three-phase pattern with bipolar patterns, hence confirming the designing equations are correct. In addition, both armature windings illustrate the identical pattern and therefore the two windings can be connected in series to simplify the operation.

Secondly, the no-load electromotive forces (EMFs) of the connected armature windings with the HTS-field excitation of $15 \mathrm{~A} / \mathrm{mm}^{2}$ at the base speed $300 \mathrm{rpm}$ are shown in Fig. 7. The results show that the proposed machine consists of the trapezoidal patterns, which is suitable for the BLDC conduction scheme. Meanwhile, the developed no-load EMFs are within the expected voltage level, with the armature connected windings.

Thirdly, the developed torque waveforms of the proposed machine are shown in Fig. 8. It can be shown that the rated average torques of the left rotor, the right rotor, and both rotors are $108.6 \mathrm{Nm}, 108.7 \mathrm{Nm}$ and $216.8 \mathrm{Nm}$, respectively. The results confirm that the torque components in the two sided-rotors can be integrated perfectly, hence achieving the balanced resultant torque. In addition, it can be shown that its torque ripple is approximately $27.8 \%$, which is comparable with those of the conventional magnetless machines are [5]. These high torque density and low torque ripple advantages are particularly desirable for the HEV direct-drive applications [2]. Moreover, the cogging torque of the proposed machine is shown in Fig. 9. It can be shown the peak amplitude of the cogging torques is about $12.5 \mathrm{Nm}$ and this value is within the acceptable range, which is only $5.77 \%$ of its rated torque.

Lastly, the flux-regulating performances of the AF-FRHTS machine are shown in Fig. 10. The HTS-field excitation of the proposed machine can be easily controlled, therefore providing the flux-regulating capability. Without controlling the flux densities, the output voltage increases along with the operating speeds. On the other hand, by regulating the flux densities, the output voltages can be kept at the same level over a wide-speed range, which is one of the most important considerations in the HEV applications.

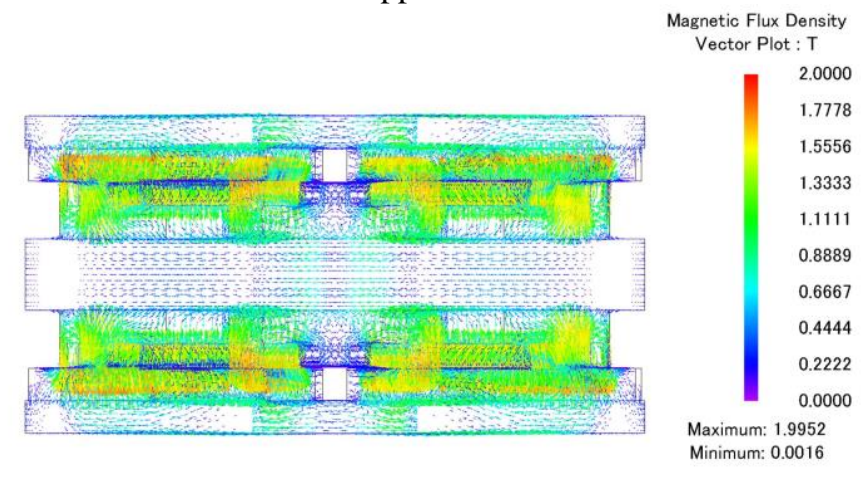

(a)
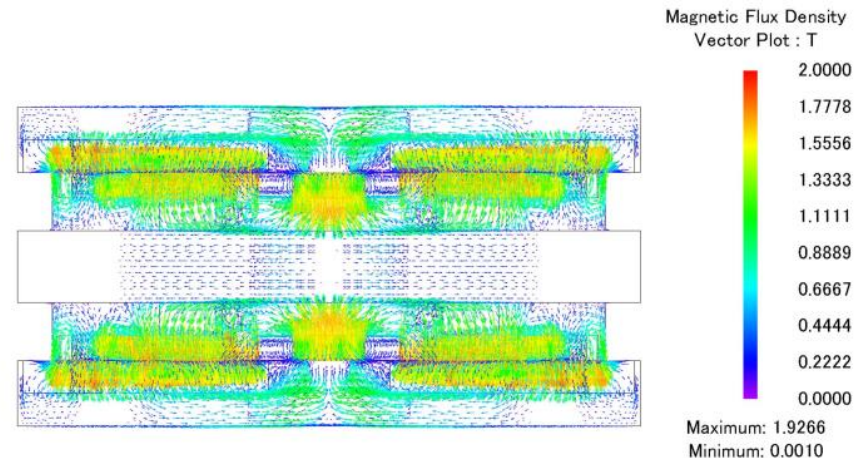

(b)

Fig. 5. No-load magnetic flux distributions: (a) Position 1. (b) Position 2.

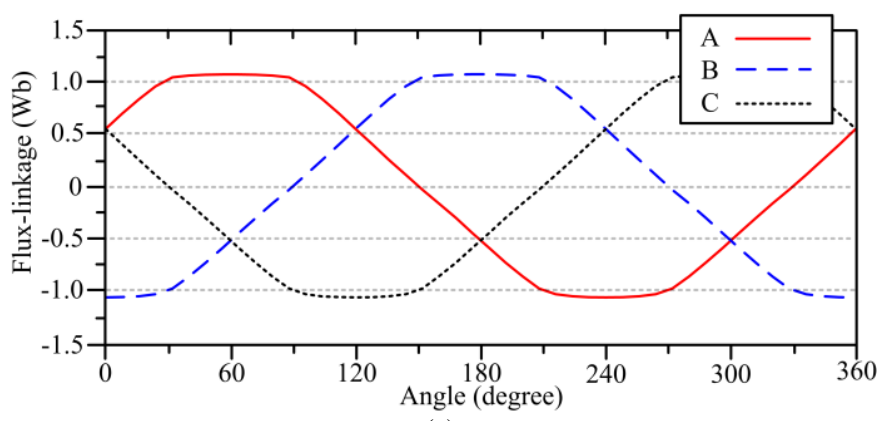

(a) 


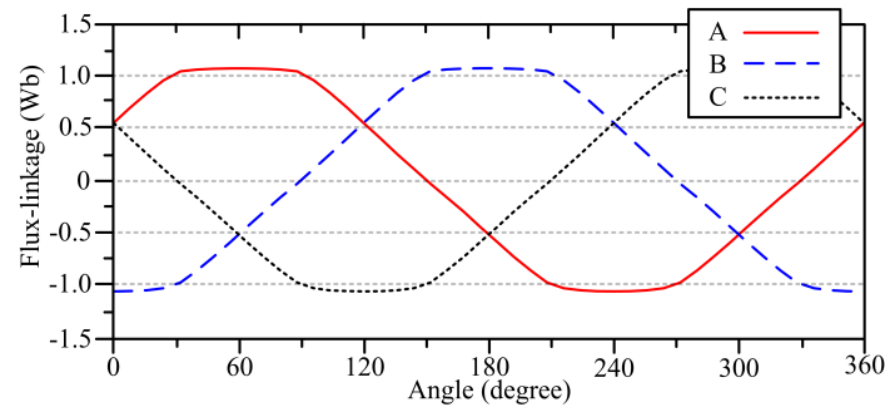

(b)

Fig. 6. Flux-linkages of AF-FRHTS: (a) Left armature. (b) Right armature.

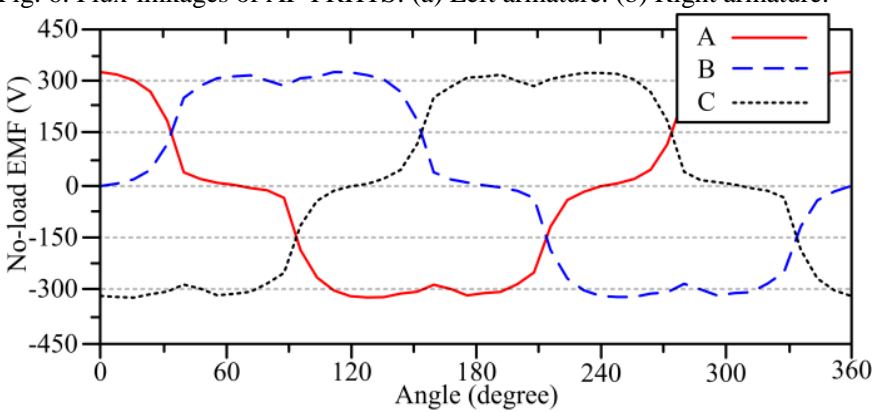

Fig. 7. No-load EMFs with HTS-field of $15 \mathrm{~A} / \mathrm{mm}^{2}$ at base speed.

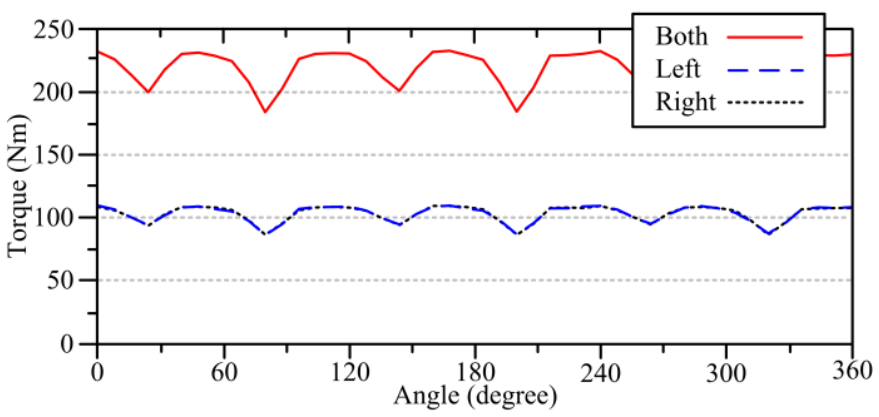

Fig. 8. Rated torque waveforms at rated conditions.

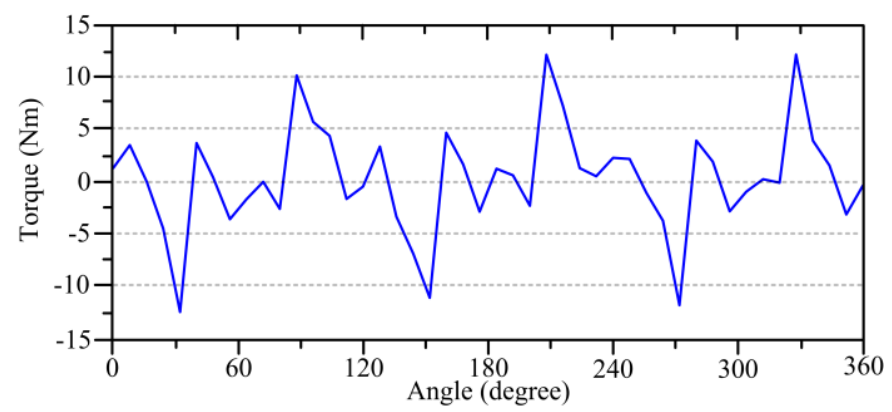

Fig. 9. Cogging torque waveforms at rated conditions.

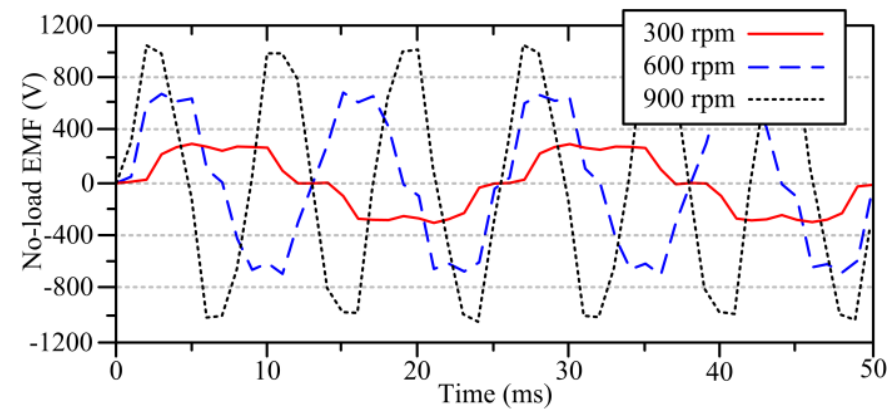

(a)

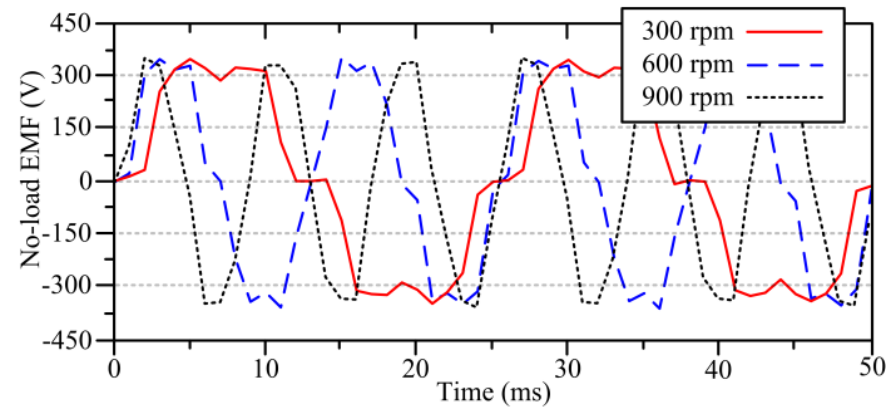

(b)

Fig. 10. No-load EMFs at various speed: (a) Without flux-regulation. (b) With flux-regulation.

\begin{tabular}{ll}
\multicolumn{2}{c}{ TABLE III. MACHINE PERFORMANCES } \\
\hline \hline & AF-FRHTS \\
\hline Power & $6800 \mathrm{~W}$ \\
Base speed & $300 \mathrm{rpm}$ \\
HTS-field excitation & $15 \mathrm{~A} / \mathrm{mm}^{2}$ \\
No-load EMF & $325 \mathrm{~V}$ \\
Rated torque & $216.8 \mathrm{Nm}$ \\
Cogging torque & $12.5 \mathrm{Nm}$ \\
Torque ripple & $27.8 \%$ \\
\hline \hline
\end{tabular}

\section{CONCLUSION}

In this paper, the new magnetless AF-FRHTS machine has been proposed and its performance is summarized in Table III. By employing the radial area as an active part for torque production, the AF-FRHTS provides better torque performances than its RF counterpart does. To be specific, the AF-FRHTS can utilize the AF structure and the bipolar fluxlinkage characteristics to result in satisfactory torque density, as compared with the PM machines [8,9]. Meanwhile, the PM material cost is an essential part of the total cost of the PM machine, so that the proposed magnetless machine can enjoy higher cost-effectiveness than the PM machines do [5, 9]. In addition, with the controllable HTS-field excitation, the proposed machine not only can result in high efficiency, but also enjoy the flux-regulating capability for the wide-speed range operation. To conclude, the proposed machine can support all the requirements for the HEV applications based on the analysis and comparisons, and hence showing the great potential in this field.

\section{REFERENCES}

[1] K. T. Chau., W. Li, and C. H. T. Lee, "Challenges and opportunities of electric machines for renewable energy," Progr. Electromagn. Res. B, vol. 42, pp. 45-74, 2012.

[2] Z. Q. Zhu, and D. Howe "Electrical machines and drives for electric, hybrid, and fuel cell vehicles" IEEE Proc., vol. 95, no. 4, pp. 746-765, Apr. 2007.

[3] R. P. Deodhar, S. Andersson, I. Boldea, and T. J. E. Miller "The fluxreversal machine: a new brushless doubly-salient permanent-magnet machine" IEEE Trans. Ind. Electron, vol. 33, no. 4, pp. 925-934, Jul. 1997.

[4] T. H. Kim,and J. Lee, "A study of the design for the flux reversal machine," IEEE Trans. Magn., vol. 40, no. 4, pp. 2053-2055, Jul. 2004.

[5] C. H. T. Lee, K. T. Chau, C. Liu, and C. Qiu "Design and analysis of a new multitoothed magnetless doubly-salient machine," IEEE Trans. Appl. Supercond., vol. 24, no. 3, p. 5200804, Jun. 2014.

[6] J. Li, and K. T. Chau, "Performance and cost comparison of permanentmagnet vernier machines," IEEE Trans. Appl. Supercond., vol. 22, no. 3, pp. 5202304, 2012.

[7] C. H. T. Lee, K. T. Chau, C. Liu, D. Wu, and S. Gao, "Quantitative comparison and analysis of magnetless machine with reluctance 
topologies," IEEE Trans. Magn., vol. 49, no. 7, pp. 3969-3972, Jul. 2013.

[8] F. Profumo, Z. Zhang, and A. Tenconi, "Axial flux machines drives: A new viable solution for electric cars," IEEE Trans. Ind. Electron, vol. 44, no. 1, pp. 29-45, Feb. 1997.

[9] C. H. T. Lee, C. Liu, and K. T. Chau, "A magnetless axial-flux machine for range-extended electric vehicle," Energies, vol. 7, no. 3, pp. 14831499, Mar. 2014.

[10] C. Liu, K. T. Chau, J. Zhong, and J. Li, "Design and analysis of a HTS brushless doubly-fed doubly-salient machine," IEEE Trans. Appl. Supercond., vol. 21, no. 3, pp. 1119-1122, Jun. 2011. 